$$
r e s e n h a
$$


AÇÃO MIDIÁTICA, n.13. Jan./Jun. 2017. Curitiba. PPGCOM-UFPR. ISSN 2238-0701

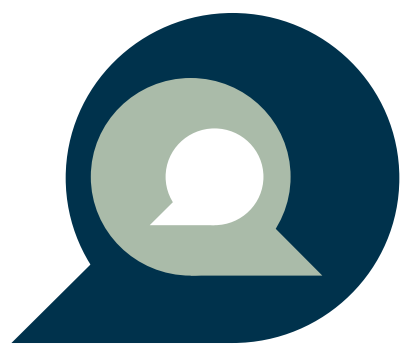




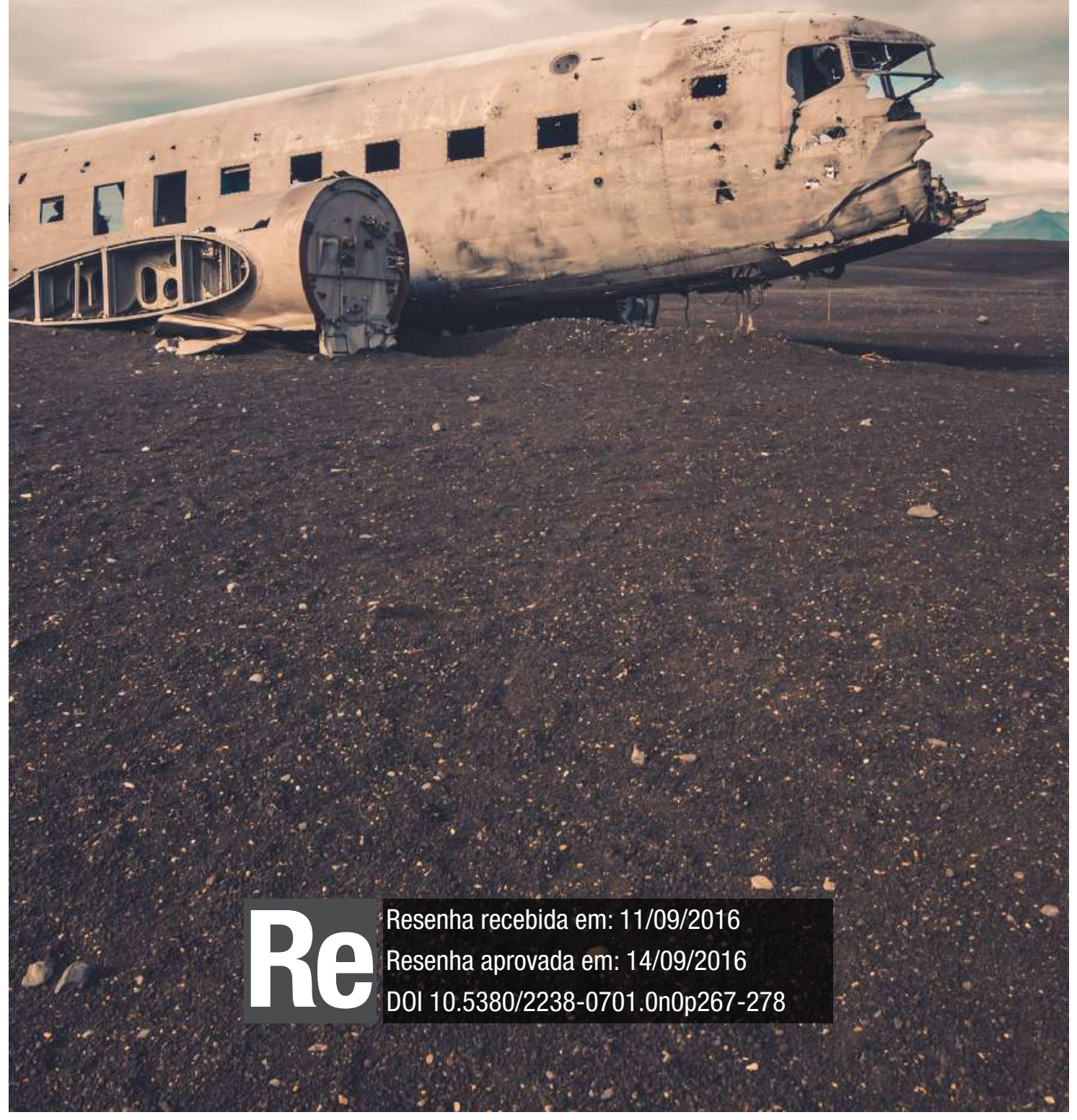


Despolitização. Clima. Mídia. 


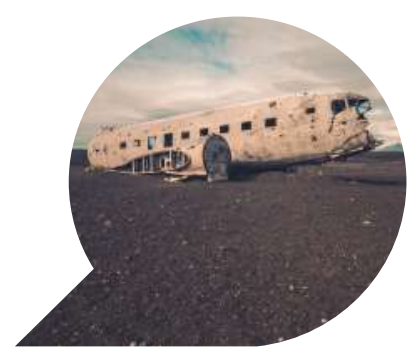

\section{A despolitização da questão climática pela mídia}

The depoliticisation of the climate change by the media La despolitización del tema climático por los medios

MYRIAN REGINA DEL VECCHIO DE LIMA ${ }^{1}$

COMBY, Jean-Baptiste. La question climatique: genèse et dépolitisation d'un problème public. Paris, ÉditionRaisond'Agir,2015.(AindainéditonoBrasil).

${ }^{1}$ Jornalista. Doutorado em Meio Ambiente e Desenvolvimento (Universidade Federal do Paraná UFPR). Bolsista Capes na Université Lyon Lumière 2, Lyon França. Pesquisadora do Grupo Clik - Comunicação e Cultura Cyber, do CNPq. Professora do Departamento de Comunicação da UFPR e dos programas de pós-graduação em Comunicação (PPGCom) e Desenvolvimento e Meio Ambiente (PPGMade), 
L ançado na França, oportunamente no período de realização da Conferência das Partes da Convenção-Quadro das Nações Unidas sobre Mudança Climática (COP-21), em Paris, em dezembro de 2015, "La question climatique" é o primeiro livro publicado por Jean-Baptiste Comby, sociólogo e pesquisador do Centro de Análise e de Pesquisa Interdisciplinar sobre Mídias (Carism) e professor do Instituto Francês de Imprensa (IFP) da Universidade de Paris II. Há algum tempo, Comby dedica-se a analisar a grande questão ambiental contemporânea, as mudanças climáticas aceleradas pelo ser humano de forma inédita, e a relação desta problemática com as instâncias políticas e econômicas, e em especial, com a mídia. Sua tese de doutorado sobre o tema e vários textos e entrevistas disponíveis em revistas científicas e na imprensa já prenunciavam que uma publicação de maior fôlego viria a seguir.

As alterações climáticas constituem um dos pontos mais enfáticos da era antropocênica, na qual vivemos, que de acordo com o Prêmio Nobel de Química em 2000, o holandês Paul Crutzen, é aquela na qual o ser humano se tornou "a principal força geológica" do planeta. A geração de gases de efeito estufa, a partir das atividades econômicas e modos de vida, que provoca alterações climáticas, representa uma das maiores evidências desta interferência humana ostensiva sobre o sistema natural do planeta. Para Jean-Baptiste Fressoz (2016:6), historiador do CNRS (Centre National de la Recherche Scientifique), o atual estágio das mudanças climáticas e as mudanças geológicas e geográficas já anunciadas (algumas em desenvolvimento), causadas pelas formas de produção econômica hegemônicas, implicam para seu enfrentamento toda uma mudança nos hábitos e valores de consumo da sociedade. E é precisamente este o ponto mais complicado do imbróglio climático contemporâneo, uma vez que, ao se pensar sobre uma realidade europeia, por exemplo, é muito mais fácil fazer a transição energética, deixando a energia nuclear de lado, do que ser contra o transporte aéreo massivo ou o automóvel individual (FRESSOZ, 2006:6). Assim, neste estágio, as questões ligadas às alterações climáticas adquirem uma dimensão muito mais econômica e, portanto, político-ideológica, do que propriamente científico-ecológica.

E aí se insere um dos pontos-chave do livro de Comby, que alega que a mídia, ao potencializar simbolicamente as alterações climáticas (tema que a princípio o autor considera ter um potencial de crítica radical), promove uma "despolitização" do problema, o que leva a um 
impasse e a medidas maquiadoras (le toilettage de la question climatique), que não darão conta de seu enfrentamento. Para Comby, estudar o debate público sobre a questão climática na França nos anos recentes, especialmente a partir de 2000, conduz à observação de como o modelo capitalista resiste de maneira inexorável - basta entender como tal modelo criou e se apropriou da ideia de um desenvolvimento sustentável para reinventar seus mercados e recursos de marketing sob o traço do "verde", com um novo discurso eco empresarial. Comby alega que se debruçar analiticamente sobre este debate é também uma forma de se perguntar sobre as condições possíveis para uma redefinição ideológica e das estruturas sociais dominantes (2015:7). Esta colocação, feita já na Introdução do livro - Un problème publique individivualisé - situa para o leitor a posição do pesquisador: ele condena as lógicas econômicas e políticas que estabelecem a catástrofe ecológica em curso, afirmando que os responsáveis pela marcha implacável destas lógicas - governos e empresas - têm na imprensa uma grande aliada, ao construir junto aos jornalistas, grandes mediadores sociais contemporâneos, uma visão moralizante que conclama os cidadãos a contribuírem para enfrentar o problema, sensibilizando-os para ações individuais, ao mesmo tempo que impõe uma visão despolitizada da questão climática, promovendo, de certa forma, uma inversão de responsabilidades.

$\mathrm{O}$ pesquisador francês destaca que as mudanças ligadas ao clima e suas consequências constituem desde o final dos anos 2000 uma questão preponderante na mídia francesa, "a ponto de aparecer como uma preocupação central para os decisores políticos” (2015: 7), constatação que pode ser ampliada e aplicada a um grande número de países. Mas, segundo o pesquisador, isto vem acompanhado de um paradoxo - tamanha visibilidade do tema também o transforma em "uma grande banalidade" e suas questões se tornam um lugar comum tanto nas discussões oficiais quanto nas conversações diárias.

A grande virtude do livro é que o texto não se limita às opiniões e visões do autor (que são enfáticas e construídas argumentativamente). Ao contrário, em grande parte o conteúdo se baseia na análise de um quadro empírico consistente, resultado de sua pesquisa de doutorado, concluída em 2008, orientada por Rémy Rieffel, do IFP (Créer um climat favorable. Les enjeux liés aux changements climatiques: valorisation publique, médiatisation et appropriations au quotidien). A versão reescrita, atualizada e ampliada da tese, resultou em cinco capítulos, acompanha- 
dos de Introdução e Conclusão, além de anexos e do posfácio Midiatização do Clima entre 2007 e 2011 na França, denominado pelo autor como "um quadro globalmente imutável". Foram perto de 70 entrevistas realizadas com jornalistas ligados à cobertura ambiental nas mídias generalistas nacionais francesas, e com suas fontes privilegiadas: cientistas e especialistas, agentes de Estado, membros de associações e organizações não governamentais, mas também especialistas em comunicação. Comby entende a intervenção destes atores sociais no campo midiático como uma mobilização legitimadora, mas em boa parte também conformista, e sobre isso discorre no capítulo 2 (Mobilisiation des scientifiques et expertise légitimante).

Foram ainda analisadas 663 reportagens sobre os desafios climáticos em telejornais noturnos das emissoras TF1 e France2, grandes canais da TV aberta francesa, entre 1997 e 2006. As análises permitiram caracterizar o tratamento jornalístico sobre a questão climática, colocando em evidência as abordagens e direcionamentos induzidos pelos argumentos de "valor notícia" conformista, resultado analítico que dialoga coerentemente com as considerações feitas no primeiro capítulo (Un traitement journalistique conformante). Os dados ainda foram reforçados para a versão livro, acrescentando-se uma análise dos mesmos telejornais, mas com as notícias do período 2007-2011, o que permitiu a elaboração do posfácio da publicação.

Pode-se, nesta altura, perguntar: o que um livro que apresenta uma pesquisa sobre o tema das mudanças climáticas e seus imbricamentos políticos e midiáticos na França pode contribuir para os interessados sobre o assunto no Brasil? A resposta é clara: muito. A formação sociológica do autor parece colaborar decisivamente para que a obra supere a colocação de algumas variáveis explicativas pouco satisfatórias sobre como as mudanças climáticas têm atraído a atenção dos diversos públicos em diferentes países. Comby enfatiza que, de forma ampla, comentaristas e mesmos pesquisadores das ciências sociais estudiosos do fenômeno costumam atribuir a atenção sobre o problema aos eventos climáticos extremos, como a onda de calor (canicule) na França em 2003, considerado um momento de mudança de opinião sobre a questão. Ou, em um exemplo brasileiro, poderíamos acrescentar a escassez hídrica (seca) no estado de São Paulo, em 2014-2015. O pesquisador cita, inclusive, uma outra publicação que contém exemplos de eventos climáticos, políticos, culturais e científicos que são relacionados pelos 
autores aos registros sobre mudanças climáticas nas agendas midiáticas, políticas e de opinião, que se retroalimentam entre si. Ele concorda que todos esses eventos aprofundam a dramatização, revalorização e manutenção do discurso midiático sobre o tema. Mas, para ele, essa é uma explicação pouco satisfatória, até porque, no seu entendimento, os efeitos decorrentes de tais eventos sobre a valorização pública do problema são difíceis de serem objetivados. Neste ponto da argumentação, ele recorre a Bourdieu, Chamboredon e Passeron (1968) para relembrar que o conhecimento imediato é sempre uma ilusão (2015: 206) e que o olhar sociológico é cauteloso com relação a estas leituras factuais, típicas da mídia, que se apoiam sobre causalidades conjunturais e parciais.

Um capítulo estruturante do livro é o terceiro (Des politiques de dépolitisation), no qual o autor discorre sobre "as políticas de despolitização", decorrentes das ações de merchandising das instituições públicas na área e das próprias políticas ambientais realizadas como ações públicas de comunicação (marketing governamental). Estabelecido esse ponto, ele conduz seu raciocínio para criticar o mote, tão bem recebido por setores como o da educação ambiental, da "sensibilização" do público (dos diversos públicos) conduzida por empresas e pelo governo, que ocultam os desafios da adaptação às mudanças climáticas e as desigualdades sociais no caso de exposição aos seus riscos e consequências. Esta retórica sobre a sensibilização do público serve, segundo o autor, apenas para mobilizar consensos, folclorizar alternativas e poupar os estilos de vida poluidores típicos do modelo capitalista dominante. Comby fecha sua construção argumentativa, no capítulo 5 (Un climat favorable aux groupes sociaux dominants), ao afirmar, provocativamente, que "o clima é favorável aos grupos sociais dominantes". Para isso, avança em questões como "o caráter ecologicamente insustentável dos estilos de vida socialmente valorizados" e "as relações distantes das classes populares à moral ecológica”, além de chamar atenção para o paradoxo social da chamada eco cidadania. Nesse ponto, ele chama a atenção para um aspecto para o qual se dá pouca ou nenhuma atenção no Brasil: a politização ecológica em um sentido não partidário, mas de responsabilização dos setores público e privado a partir de reivindicações e pressões de setores organizados da sociedade.

Pode-se observar que, se a tese de Comby foi atualizada com um posfácio, realizado a partir de uma nova etapa de pesquisa em 2011, 
o lançamento do livro demorou um tempo razoável para ocorrer no final de 2015. Entretanto, é certo que não há mudanças significativas sobre os aspectos abordados por Jean-Baptiste Comby, desde os anos de sua pesquisa, a não ser o fato dos setores jornalísticos terem passado por um histórico processo de tecnização em seu repertório de ações de produção e distribuição de notícias, e que esta intensa etapa de midiatização pela via da Web, também atingiu as organizações ambientais que passaram a realizar ações coletivas em rede para atingir seus públicos. Mas, tais metamorfoses estruturais, não alteraram muito a forma de se comunicar sobre a questão das mudanças climáticas.

De fato, pesquisas recentes (LIMA et al, 2016) realizadas sobre um veículo totalmente online, o The Huffington Post, tanto na versão brasileira quanto francesa, revelam que, apesar dos conteúdos estarem disponibilizados na rede - com o uso de inúmeros recursos multimídia, e serem estruturados do ponto de vista do consumo e fruição pelas plataformas móveis por onde são distribuídos, assim como o fato de serem pautados por uma nova forma de medição de audiência, via clicks, do público - , seus conteúdos permanecem praticamente iguais àqueles divulgados pelos noticiários de televisão analisados por Comby em períodos anteriores (ressalve-se a oportunidade de aprofundamento de alguns aspectos do problema pela publicação bastante significativa de artigos de opinião, em blogs). Pode-se falar, então, que, desde 2000, permanecem nos conteúdos jornalísticos os mesmos argumentos discursivos sobre a construção da atualidade no que diz respeito às mudanças climáticas, suas causas e consequências, alterando-se apenas o pano de fundo de eventos e seus contextos.

Esta permanência do discurso sobre a situação e o agravamento das questões climáticas globais nos conduzem a uma grande questão, muito bem colocada em resenha francesa sobre o livro de Comby, publicada na revista Sociologie do CNRS. Nela, Cyprien Tasset (2016), do Instituto de Pesquisa Interdisciplinar sobre Desafios Sociais (Iris-Ehess), enquadra a obra de Comby como uma resposta sobre o que muitos perguntam atualmente: como a questão do aquecimento climático, com toda a atenção pública que desperta nas democracias ocidentais, depois de tanto tempo, não corresponde a mudanças políticas proporcionais à gravidade atribuída ao fenômeno pelos cientistas? Esta é a questão de fundo que surge com frequência para todos: ambientalistas e ecologistas, comunicadores e jornalistas, cientistas sociais e naturais, políticos e empresá- 
rios; e deve aparecer também para muitos cidadãos preocupados com o futuro da sociedade humana no planeta, ou até, do próprio planeta. Para Comby, uma das respostas possíveis para a aparente estagnação da situação socioambiental, em que se incluem as alterações climáticas, é que ela se dá pela via do esvaziamento político da questão, o que leva a uma "não mudança" e à repetição dos mesmos discursos há anos.

\section{REFERÊNCIAS}

FRESSOZ, Jean-Baptiste. Le Journal. Genève, Suisse. n.122, 13 Oct-3 Nov, 2016. TASSET, Cyprien. Sociologie, CNRS, France, n. 3, v.7, 2016.

LIMA, Myrian De Vecchio; FORT, Mônica; FIEBIG, Manoela; GERN, Augusta; ÁVILA, Otávio C. Ênfases jornalísticas na cobertura da COP 21 (Paris, 2015) nas versões norte-americana, brasileira e francesa do site The Huffington Post. Curitiba, Desenvolvimento e Meio Ambiente, n. 40, p.77-99. 2017

COMBY, Jean-Baptiste. La question climatique: genèse et dépolitisation d'un problème public. Paris, Édition Raison d'Agir, 2015. 
AÇÃO MIDIÁTICA, n.13. Jan./Jun. 2017. Curitiba. PPGCOM-UFPR. ISSN 2238-0701

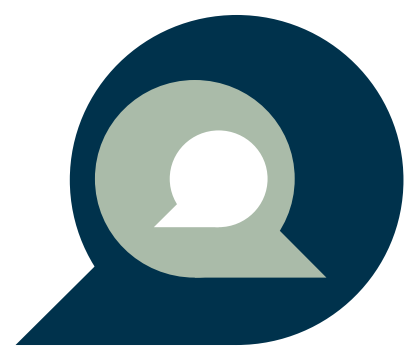

